\title{
Diagnostic and Prognostic Value of N-Terminal Brain Natriuretic Peptide in Patients of Heart Failure
}

\author{
Ashish Prakash Anjankar¹, Sandip Deepak Lambe², Kanchan Sandip Lambe ${ }^{3}$ \\ 1Department of Biochemistry, JNMC, Wardha, Maharashtra, India. ${ }^{2}$ Department of Biochemistry, SMBT IMS \\ \& RC, Dhamangaon, Nashik, Maharashtra, India. ${ }^{3}$ Department of Conservative Dentistry \& Endodontics, \\ SMBT IDS \& R, Dhamangaon, Nashik, Maharashtra, India.
}

\section{ABSTRACT}

\section{BACKGROUND}

Heart failure is a clinical condition in which a deviation in normal cardiac structure or function is accountable for the incapability of the heart to eject or fill with blood at a proportion proportionate to the requirements of the metabolizing tissues. The detection of heart failure is based on clinical symptoms, signs, chest $\mathrm{x}$ rays and reaction to the treatment. BNPs are released by the heart ventricles in reaction to volume load or pressure load physiologically and they function to counteract rennin angiotensin system, cause vasodilatation and natriuresis. The BNP evaluation has gained approval already in the recommendations of European Society of Cardiology for the detection of heart failure. We wanted to study the potential of a new unconventional assay plasma N-Terminal pro BNP in detecting cardiac failure, and correlate the levels of plasma N-Terminal pro BNP with the severity of the cardiac failure and levels of plasma N-Terminal Pro BNP with systolic and diastolic dysfunction.

\section{METHODS}

It was an analytical cross-sectional study conducted among 50 patients with clinical features of cardiac failure attending medicine OPD and emergency department of the hospital for the duration of 18 months and an equal number of age and sex equivalent fit controls. In subjects with clinical features of heart failure, and in healthy controls, $2 \mathrm{~mL}$ of blood sample is drawn for assay of plasma $\mathrm{N}$-Terminal pro BNP within half an hour of presentation. Using biomedical kit plasma N-T pro BNP concentration was measured. The entire period of the assay is $18 \mathrm{~min}$. Detectability range by this method of $\mathrm{N}-\mathrm{T}$ proBNP is $5 \mathrm{pg} / \mathrm{mL}$ to $35,000 \mathrm{pg} / \mathrm{mL}$.

\section{RESULTS}

Cases comprised of 28 males and 22 females with a mean age 50.80 (13.11) years while controls comprised of 28 males and 22 females with a mean age 50.86 (12.7) years. There was a statistically noteworthy difference in Mean N-T pro BNP between case and control groups, NYHA Class, and age group. Mean N-T pro-BNP is not significantly different at discharge and on $2^{\text {nd }}$ follow-up. For the rest of the diagnoses, there is a notable difference in Mean N-T pro BNP at discharge and on 2nd follow-up.

\section{CONCLUSIONS}

Plasma N-Terminal pro BNP levels are useful from therapeutic point of view (aggressive therapy if needed e.g. Heart transplantation / bilateral pacemaker or invasive therapy may be planned by $\mathrm{N}-\mathrm{T}$ pro BNP levels).

\section{KEY WORDS}

Brain Natriuretic Peptide, Cardiac Failure, Diagnostic Value
Corresponding Author: Dr. Sandip Deepak Lambe, Department of Biochemistry, SMBT IMS \& RC, Dhamangaon, Nashik, Maharashtra, India. E-mail: drsandiplambe@gmail.com

DOI: $10.14260 / j e m d s / 2020 / 474$

How to Cite This Article: Anjankar AP, Lambe SD, Lambe KS Diagnostic and prognostic value of $n$ terminal brain natriuretic peptide in patients of heart failure. J Evolution Med Dent Sci 2020;9(31):2176-2180, DOI: 10.14260/jemds/2020/474

Submission 20-04-2020,

Peer Review 21-06-2020,

Acceptance 29-06-2020,

Published 03-08-2020.

Copyright (c) 2020 JEMDS. This is an open access article distributed under Creative Commons Attribution License [Attribution 4.0 International (CC BY 4.0)] 


\section{BACKGROUND}

Heart failure is a usual and very morbid disease. It is an increasing worldwide epidemic. The Economic burden innovated by Heart failure is quite enormous and is expected to grow dramatically in light of current clinical and demographic trends, particularly with the recent improvement in survival rate after myocardial infarction due to early thrombolysis and revascularization surgery. Thus, it is predicted that the disease load of Heart Failure will nearly increase two fold over the next thirty to forty years. ${ }^{1}$

Heart failure is a clinical condition in which a deviation in normal cardiac structure or function is liable for the incapability of the heart to eject or fill with blood at a rate proportionate with the necessities of the metabolizing tissues. $^{2}$

The detection of Heart failure is based on clinical symptoms, signs, chest $\mathrm{X}$ rays and reaction to the treatment. Echocardiography detects the particular structural and functional deformities seen in the syndrome but do not solely decide the detection of Heart failure. The severity of clinical manifestations is commonly described according to criteria developed by the New York Heart Association. ${ }^{3}$

The signs and symptoms may be challenging to identify in patients with acute respiratory distress particularly in cases where quick diagnosis and treatment are desired. The echocardiogram is useful to diagnose the existence of systolic defect. However, studies have indicated that a 50\% of patients with well-established clinical Heart failure have an absolutely normal systolic work (diastolic heart failure). In addition to it, nearly half of patients with systolic defect have no changes of Heart failure (asymptomatic ventricle defect). ${ }^{4}$

Hence a decreased ejection fraction does not ascertain the diagnosis of Heart failure. Moreover, the availability of echocardiography is less in critical care settings. Therefore, there has been a sudden rise in the interest of physicians in a cheap, commonly available, easily accessible diagnostic test that indicates the physiology similar to patients with systolic Heart failure and diastolic Heart failure. ${ }^{5}$

BNPs are released from the heart ventricles in reaction to volume load or pressure load physiologically and they function to counteract rennin angiotensin system, cause vasodilatation and natriuresis.6,7,8 Detection of plasma levels of N-Terminal Pro BNP is sanctioned by the FDA as a test to support in the detection of Heart failure. Approval of this diagnostic assessment was centred on many research studies that explored the efficacy of Brain Natriuretic peptide in assessing patients coming with symptoms like dyspnoea. These studies have indicated that BNP differentiates correctly among Heart failure and non-Cardiac dyspnoea in various critical care hospitals and primary care centres. $9,10,11,12$

The BNP test has been approved already in the European Society of Cardiology recommendations for the detection of Heart failure. ${ }^{13}$ This study has been performed to study the role of plasma N-Terminal Pro BNP in the detection of Heart failure and evaluating plasma N-Terminal Pro BNP levels in various forms of systolic and diastolic Heart failure.

We wanted to study the potential of new unconventional assay plasma N-terminal pro BNP in detecting the cardiac failure, and correlate the levels of plasma $\mathrm{N}$-Terminal pro BNP with the severity of the cardiac failure and levels of plasma N-Terminal Pro BNP with systolic and diastolic dysfunction.

\section{METHODS}

It was an analytical cross-sectional study comprised of 50 patients with clinical features of cardiac failure attending medical OPD and emergency department of the hospital for the duration of 18 months and the equal number of age and sex-matched healthy controls.

A detailed clinical history was recorded regarding age, duration of symptoms, ischemic heart disorders, rheumatic heart disorders, hypertension, diabetes, dyslipidaemias, smoking, alcoholism. All patients undertook a comprehensive clinical examination comprising examination of pulse, blood pressure, respiratory, cardiovascular and central nervous systems.

Biochemical tests like random blood glucose, blood urea, complete blood picture, serum creatinine and electrolytes were done. ECG, chest x-ray, 2D echocardiogram and ultrasound abdomen were done for every case of a control subject. Follow up of patient is done over one and half month monitoring readmission of the patient for the same complaints or worsening of symptoms or regular follow up. $\mathrm{N}$ Terminal-pro BNP levels are measured during the second admission.

\section{Sample Size}

The sample size for the study was found out by using the formula as per the guidelines from Statistician from Community Medicine department:

Sample size

$(n)=\frac{4 \mathrm{pq}}{\mathrm{E} 2}$

\section{Inclusion Criteria}

- Patients with breathlessness because of heart failure as per.

- Framingham's criteria.

\section{Exclusion Criteria}

- Age $<15$ years.

- Sepsis.

- Pulmonary disease.

- Renal failure.

\section{Study Protocol \\ In subjects with clinical presentation of heart failure and in healthy controls, $2 \mathrm{~mL}$ of blood sample is drawn for assay of plasma N-Terminal Pro BNP within half an hour of presentation. Blood is immediately centrifuged after collecting in EDTA bottle and plasma assay is carried out by Electrochemoluminescent Immunoassay (ECLIA). Blood was gathered in a ice-cold sample tube and rotated in a centrifuge instantaneously. The plasma is kept at -80 degrees until N-T pro BNP assay is carried out. Using biomedical kit plasma N-T}


pro BNP concentration is measured. The kit is a competitive ELISA destined to detect the immune reactive $\mathrm{N}-\mathrm{T}$ pro-BNP. The principle of this ECLIA is principled on detection of two polyclonal antibodies: a biotinylated and a ruthenium derivative-labelled antibody. The entire period of the assay is $18 \mathrm{~min}$. Detectability Range by this method of N-T proBNP is $5 \mathrm{pg} / \mathrm{mL}$ to $35,000 \mathrm{pg} / \mathrm{mL}$.

\section{Statistical Analysis}

Quantitative data was represented as Mean \pm SD. Statistical analysis was done using SPSS software version 17. P $<0.05$ was considered statistically significant.

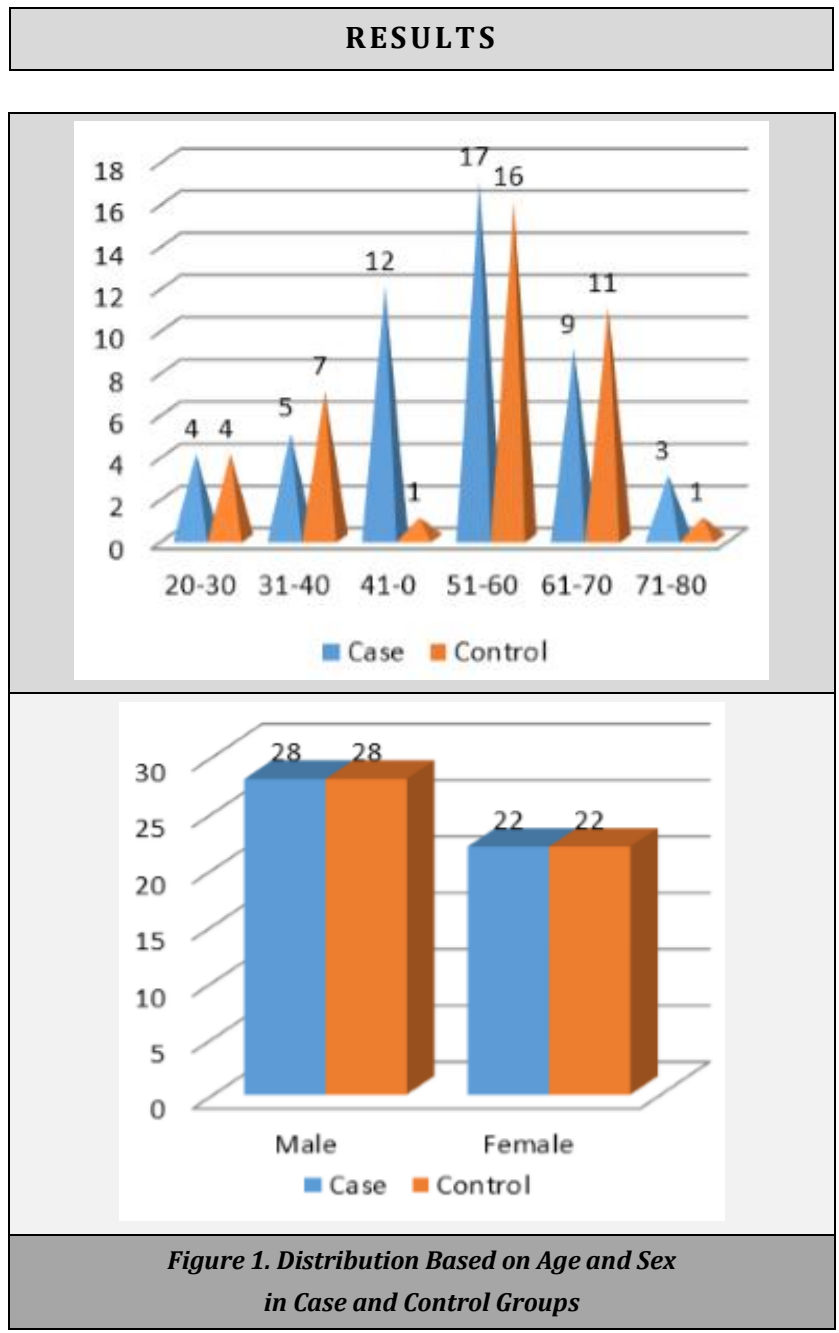

There were 28 males and 22 females in case group with mean age 50.80 (13.11) years and 28 males and 22 females in the control group with mean age 50.86 (12.7) years.

As per table 1, there is a significant difference in Mean $\mathrm{N}$ $\mathrm{T}$ pro BNP between case and control groups, NYHA Class, and age group.

As per table 2, for only stable patients, Mean N-T pro-BNP is not significantly different at discharge and on II follow-up. For rest of the diagnoses, there is a significant difference in Mean N-T pro BNP at discharge and on II follow-up.
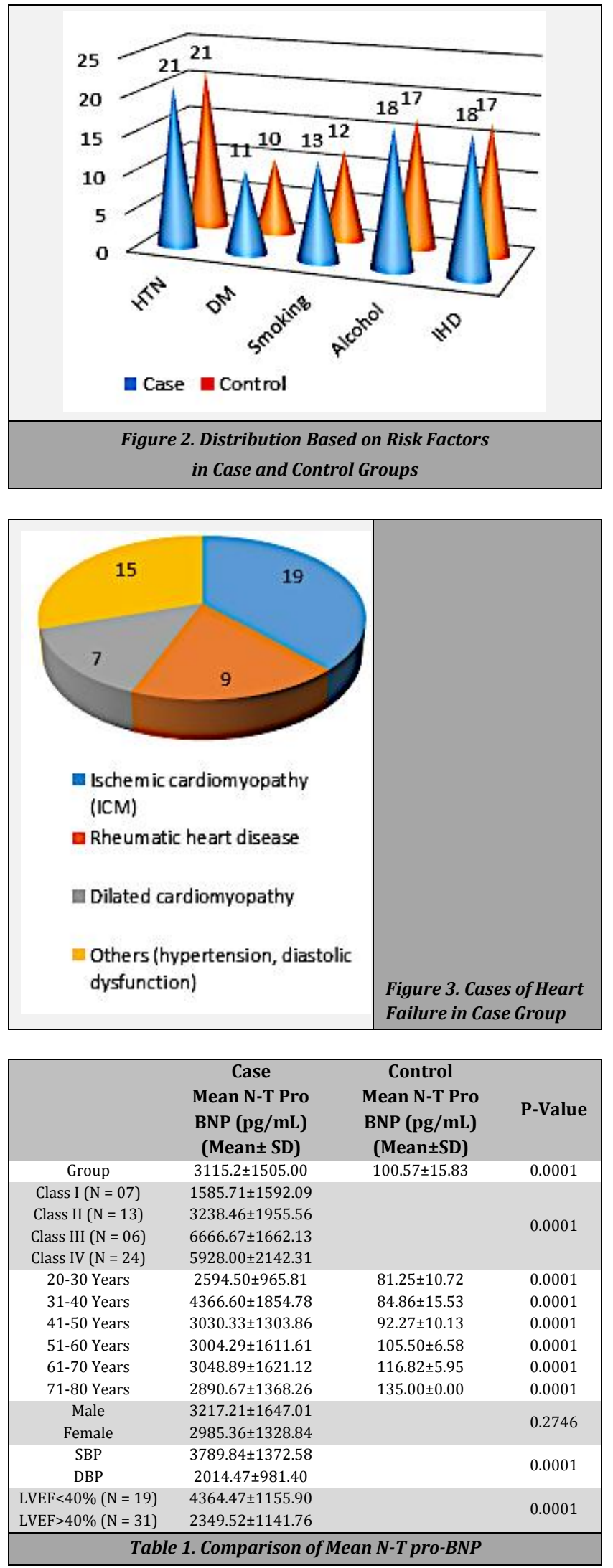

\begin{tabular}{|cccc|}
\hline \multirow{4}{*}{ Diagnosis } & \multicolumn{2}{c|}{$\begin{array}{c}\text { Mean N-T Pro BNP (pg/mL) } \\
\text { (Mean } \pm \text { SD) }\end{array}$} & P-Value \\
& At Discharge & II Follow-Up & \\
CCF $(\mathrm{N}=20)$ & $3806.50 \pm 1177.05$ & $4662.00 \pm 1180.45$ & 0.0001 \\
Stroke $(\mathrm{N}-10)$ & $3954.40 \pm 583.03$ & $5590.20 \pm 877.44$ & 0.0001 \\
CCF $/$ Death $(\mathrm{N}=9)$ & $5974.44 \pm 886.63$ & $8358.89 \pm 1663.75$ & 0.0001 \\
Stable $(\mathrm{N}=11)$ & $1116.54 \pm 320.43$ & $1009.09 \pm 410.98$ & 0.0605 \\
\hline \multicolumn{4}{|c|}{ Table 2. Association between Diagnosis and Mean $\mathbf{N}$-T pro BNP } \\
\hline
\end{tabular}




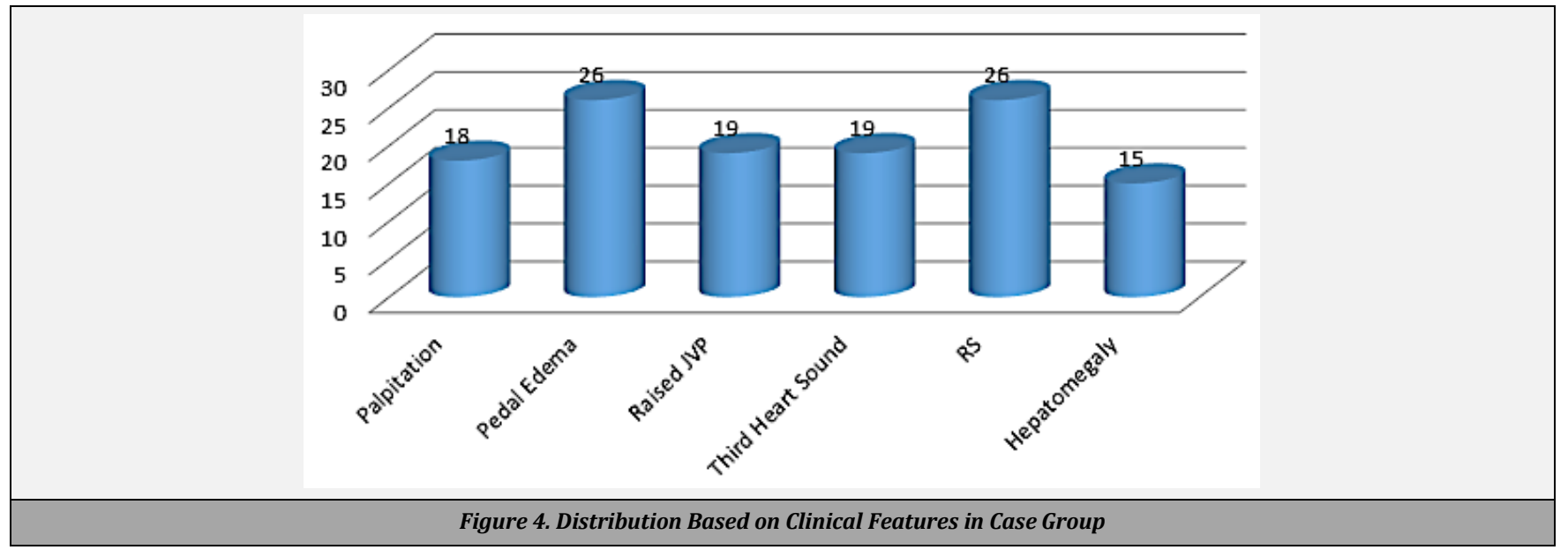

\section{DISCUSSION}

The present study was carried out in the department of Biochemistry \& General Medicine of a tertiary care centre. 50 patients of breathlessness of cardiac cause according to Framingham's criteria were taken as cases, and 50 healthy age and sex-identical asymptomatic subjects were considered as healthy controls.

In the present study, plasma $\mathrm{N}$-terminal pro BNP measurements in cases $(n=50)$ and controls were compared. Mean plasma N-terminal pro BNP level in cases of cardiac failure is $3115.2 \mathrm{pg} / \mathrm{mL}$, and in the control group, it is 100.84 $\mathrm{pg} / \mathrm{mL}$. This shows that there is a significant rise in plasma $\mathrm{N}$ terminal pro-BNP in cases of cardiac failure. This was correlated with previous studies of Januzzi JL Jr Camargo CA et al. 14

Plasma N-terminal pro BNP measurements in cases of cardiac failure according to NYHA functional classification showed that significant increase in the measurement with increasing severity of cardiac failure (NYHA class I-1585.71 $\mathrm{pg} / \mathrm{mL}, \mathrm{v} / \mathrm{s}$ NYHA class II- $3238.46 \mathrm{pg} / \mathrm{mL}$, v/s NYHA class III$6666.67 \mathrm{pg} / \mathrm{mL}$, NYHA IV- $5928.00 \mathrm{pg} / \mathrm{mL}$ ). The present study result is in correlation with study done by Jacob $\mathrm{V}$ Rose et al. of CMC Vellore. ${ }^{15}$

Plasma N-terminal pro BNP measurements in cases with systolic and diastolic dysfunction showed levels are significantly high in systolic dysfunction alone compared to diastolic dysfunction alone $(3789.84 \mathrm{pg} / \mathrm{mL}$ in systolic dysfunction alone vs $2014 \mathrm{pg} / \mathrm{mL}$ in diastolic dysfunction). ${ }^{16,17}$

Plasma N-terminal pro BNP measurements in cases of cardiac failure with LVEF $<40 \%$ and LVEF $>40 \%$ indicated significant increase in measurement in patients with LVEF $<40 \%$ compared to LVEF $>40 \% \quad(4364.47 \mathrm{pg} / \mathrm{mL}$ vs 2349 $\mathrm{pg} / \mathrm{mL}$ ) respectively. ${ }^{16,17}$

Plasma N Terminal BNP Levels in study showed slightly higher levels in male gender $(3217.21 \mathrm{pg} / \mathrm{mL})$ as compared to females $(2985.36 \mathrm{pg} / \mathrm{mL})$ with no significant difference in two values, though studies have shown that plasma $\mathrm{N}$ Terminal Pro BNP levels are slightly higher in females than males because of greater diastolic abnormalities and stiff ventricles in females. ${ }^{18}$
Though Plasma N-Terminal pro BNP measurements also increases with increasing age, especially after 50 years in both cases and controls which is an expected result due to decrease in clearance of the N-T pro-BNP by kidneys with increasing age. 18

Patients taken in study groups were admitted with different severity of breathlessness, so levels of Plasma NTerminal Pro BNP has not shown variation with increasing age as the severity of cardiac dysfunction as well as response to treatment is a most important cause of raised Plasma NTerminal Pro BNP.

The most common cause of cardiac failure in this study was ischemic cardiomyopathy (38\%), the second is the rheumatic heart disease (18\%), and the third is dilated cardiomyopathy. The most common symptom is shortness of breath followed by swelling of feet. The most common feature in subjects with heart failure is cardiomegaly, followed by pedal oedema, hepatomegaly, raised JVP and third heart sound.

Patients in whom Plasma N-Terminal Pro BNP values at the time of discharge are less i.e. $<1500$ came for routine follow up in OPD and no morbidity was seen in them. ${ }^{19}$ Patients with more Plasma N-Terminal Pro BNP values $>1500$ at the time of discharge were found to have poor prognosis because they were again admitted hospital with congestive cardiac failure (40\%), stroke (20\%) and $18 \%$ of them died This is compared with study done by Encourt P and Azevedo A. $20,21,22$

Thus, Plasma N-Terminal Pro BNP at the time of discharge is a good prognostic marker of cardiac function and can help to guide the therapy in patients of heart failure. ${ }^{20,21,22}$

\section{CONCLUSIONS}

Plasma N-Terminal pro BNP can be validly considered for the diagnosis of cardiac failure. In the emergency detection of the reason of dyspnoea, whether dyspnoea is due to respiratory (COPD / asthma) or cardiac cause, plasma N-T pro BNP measurements are of valuable help in ruling out cardiac failure. Plasma N-Terminal pro BNP at the time of discharge of patients from the hospital is best correlated with long term 
prognosis of patients. Plasma N-terminal pro BNP levels are useful from the therapeutic point of view (aggressive therapy if needed e.g. heart transplantation / bilateral pacemaker or invasive therapy may be planned by N-T pro BNP levels).

Financial or Other Competing Interests: None.

Financial or Other Competing Interests: None.

\section{REFERENCES}

[1] Ho KK, Pinsky JL, Levy D, et al. The epidemiology of heart failure: the Framingham study. J Am Coll Cardiol 1993;22(4 Supp A):6A -13A.

[2] Davies MK, Gibbs CR, Lip GY. ABC of heart failure. BMJ 2003:320(7230):297-300.

[3] Struthers AD. The diagnosis of heart failure. Heart 2000;84(3):334-8.

[4] Asher CR, Klein AL. Diastolic heart failure: restrictive cardiomyopathy, constrictive pericarditis and cardiac tamponade: clinical and echocardiographic evaluation. Cardiol Rev 2002;10(4):218-29.

[5] Aurigemma GP. Diastolic heart failure - a common and lethal condition by any name. $\mathrm{N}$ Engl $\mathrm{J}$ Med 2006;355(3):308-10.

[6] Vasan RS, Levy D. Defining diastolic heart failure: a call for standardized diagnostic criteria. Circulation 2000;101(17):2118-21.

[7] Levin ER, Gardner DG, Samson WK. Natriuretic peptides. N Engl J Med 1998;339(5):321-8.

[8] Mukoyama M, Nakao K, Hosoda K, et al. Brain peptide as a novel cardiac hormone in humans. Evidence for an exquisite dual natriuretic peptide system, atrial natriuretic peptide and brain natriuretic peptide. J Clin Invest 1991;87(4):1402-12.

[9] Januzzi JL, Camargo CA, Anwaruddin S, et al. The Nterminal pro-BNP investigation of dyspnea in the emergency department (PRIDE) study. Am J Cardiol 2005;95(8):948-54.

[10] Vasan RS, Benjamin EJ, Larson MG, et al. Plasma natriuretic peptides for community screening for left ventricular hypertrophy and systolic dysfunction: the Framingham heart study. JAMA 2002;288(10):1252-9.

[11] Redfield MM. The breathing not properly trial: enough evidence to change heart failure guidelines? J Card Fail 2002:8(3):120-3.
[12] Wright SP, Doughty RN, Pearl A, et al. Plasma aminoterminal pro-Brain natriuretic peptide and accuracy of heart-failure diagnosis in primary care: a randomized, controlled trial. J Am Coll Cardiol 2003;42(10):1793-800.

[13] Remme WJ, Swedberg K. Comprehensive guidelines for the diagnosis and treatment of chronic heart failure. Task force for the diagnosis and treatment of chronic heart failure of the European society of cardiology. Eur J Heart Fail 2002;4(1):11-22.

[14] Januzzi JL, Camargo CA. The N-terminal Pro-BNP investigation of dyspnea in the emergency department (PRIDE) study. Am J Cardiol 2005;95(8):948-54.

[15] Jacob. Utility of N-terminal pro-BNP in the diagnosis of cardiac failure. Indian Med J 2001;32:31-5.

[16] Bay M, Kirk V, Parner J, et al. NT-proBNP: a new diagnostic screening tool to differentiate between patients with normal and reduced left ventricular systolic function. Heart 2003;89(2):150-4.

[17] Hobbs FD, Davis RC, Roalfe AK, et al. Reliability of Nterminal proBNP assay in diagnosis of left ventricular systolic dysfunction within representative and high risk patients. Heart 2004;90(8):866-70.

[18] Redfield MM, Rodeheffer RJ, Jacobsen SJ, et al. Plasma brain natriuretic peptide concentration: impact of age and gender. J Am Coll Cardiol 2002;40(5):976-82.

[19] Salah K, Kok WE, Eurlings LW, et al. A novel discharge risk model for patients hospitalised for acute decompensated heart failure incorporating N-terminal pro-B-type natriuretic peptide levels: a European collaboration on acute decompensated heart failure: ÉLAN-HF Score. Heart 2014;100(2):115-25.

[20] Bayés-Genís A, Lopez L, Zapico E, et al. NT-ProBNP reduction percentage during admission for acutely decompensated heart failure predicts long-term cardiovascular mortality. J Card Fail 2005;11(5 Suppl):S3-8.

[21] Januzzi JL, van Kimmenade R, Lainchbury J, et al. NTproBNP testing for diagnosis and short-term prognosis in acute destabilized heart failure: an international pooled analysis of 1256 patients: the international Collaborative of NT-proBNP Study. Eur Heart J 2006;27(3):330-7.

[22] Bettencourt P, Azevedo A, Pimenta J, et al. N-terminalpro-brain natriuretic peptide predicts outcome after hospital discharge in heart failure patients. Circulation 2004;110(15):2168-74. 